\title{
Why Visual Aids Need to Be Less Visual
}

COMMUNICATION CORNER No. 14

\author{
by Philip Yaffe
}

\section{Editor's Introduction}

Each "Communication Corner" essay is self-contained; however, they build on each other. For best results, before reading this essay and doing the exercise, go to the first essay "How an Ugly Duckling Became a Swan," then read each succeeding essay.

Public speaking is not only about communicating your ideas orally, but also visually. Too many presentations are undermined by poorly chosen slides. An outstanding presentation is one that addresses two fundamental objectives, with the end goal of leaving a lasting impression on the audience. 


\title{
Why Visual Aids Need to Be Less Visual
}

\author{
COMMUNICATION CORNER No. 14
}

\section{by Philip Yaffe}

I was recently invited to a presentation by an accomplished speaker. Needless to say, his speech was well structured, his manner relaxed and confident, his eye contact and body language excellent, etc. He normally spoke without slides, but this time he felt they would reinforce and illuminate his message. They didn't. In fact, they were more of a hindrance than a help.

This is not an isolated case; it is typical. With more than 40 years as a communication consultant, I have seen countless "good" speakers give a very good oral presentation, only to undermine it with slides that detract rather than add.

Why does this happen?

Too often speakers fail to recognize slides are an integral part of the presentation, not an addon. Likewise, they fail to recognize the principles and practices that underpin the oral component of the presentation are essentially the same as those that should underpin the visual component.

As a result, the slides seem to be conceived with no real thought or structure. Having no coherent schema or checklist to guide them, otherwise accomplished speakers appear to design their slides according to whatever pleases them. They make little effort to "please" their listeners, i.e. enhance the communication, which is the only real reason for using slides in the first place.

So how can you design and use slides that add to your presentation rather than detract from it?

Before you can do anything well, you need to understand why you are doing it. Slides should achieve two fundamental objectives.

1. Help the speaker deliver a better presentation

2. Help the listeners better understand the presentation 


\section{Basic Principles}

There is a false belief that most slides-if not all of them-should be illustrated. If your objective is to show the beauty of a tourist destination, the genius of an architectural concept, the difficulty of a manufacturing procedure, etc., then illustrations make sense. But illustrations that are not germane to the presentation can be distracting and therefore detrimental.

Don't believe it? Then try this experiment. Open a newspaper or magazine to any page with a photo. Try looking only at the upper left hand corner of the photo and nowhere else. It is virtually impossible. The moment the eye is confronted with a photo, drawing, diagram, etc., there is a natural tendency to wander all over it.

Many speakers commit the error of using illustrations when they really aren't needed. Imagine a speaker telling the audience to look only at the center of a photograph or complex diagram, because that is the only part he wishes to talk about. But while he is talking about the center, much of the time the audience will be looking somewhere else, because they can't help it. This constant movement around the image results in split attention, diminishing the impact of the speaker's comments.

The adage that "a picture is worth a thousand words" is undeniably true. But this is exactly the problem. An image often says much more than what the speaker wants it to say. So while you may wish to use only 300 or 400 of those "words" to make your point, the audience will be absorbing all one thousand of them. You have no idea how they may be interpreting-or misinterpreting - this extraneous information. But you can be certain that whatever it is, it is not helping your cause.

In short, if your presentation does not naturally call for images, illustrated slides should be avoided. If it does naturally call for images, use slides with as little extraneous content as possible. And only when they are necessary. The common practice of leaving an image on the screen just to have something on the screen while the speaker is talking about something else is counterproductive. When no image is required, replace it with a simply a soft color as a placeholder until the next image is required. Better yet, turn the project off and turn up the lights so that the audience can see who is talking to them rather than remaining just a disembodied voice.

In the debate "to illustrate" or "not to illustrate" the question invariably arises: Aren't text slides boring? Shouldn't they be avoided? In a word: No. For two reasons: 
1. Text is visual. The fact that the audience is looking at it makes it a kind of illustration. Therefore, full care should be taken to arrange the text on the slide to maximize attractiveness and ensure readability.

2. Only the speaker can be boring. The value of slides-text, illustrated, or combinedtotally depends on how effectively the speaker designs and uses them.

In short, if your presentation does not naturally call for images, illustrated slides should be avoided. If it does naturally call for images, use slides with as little extraneous content as possible.

\section{Elements of Effective Text Slides}

Effective text slides generally consist of two parts: the heading and the body.

The heading announces the subject to be discussed, thereby preparing the listeners for the information they are about to receive. The body serves to examine specific aspects of the subject announced in the heading. This is the real focus of the slide, and where the most care must be taken.

Whenever possible, the body should first make a general statement, which serves to emphasize a single key idea. The rest of the body should then reinforce the key idea by supporting or enlarging on the general statement. This often takes the form of bullet points:

- General Statement

- Support info

- Support info

- Support info

- Support info

Writing the text. Let's agree that the moment the slide appears on the screen, people will want to read it. Let's also agree they read at different rates, so some will finish sooner than others. Finally, let's agree that those who finish rapidly are likely to let their minds wander to thoughts other than the presentation.

This implies loss of attention, which is the last thing you want to happen. So how do you prevent it? 
One way is to keep the quantity of text on the screen to an absolute minimum. The less people have to read, the more likely they will finish more or less together, so there is less opportunity for their minds to wander.

Minimal text on the screen confers another significant benefit. It encourages people to immediately re-focus their attention on the speaker for elaboration of what they have just read. To abuse a metaphor, you could say the slide is the appetizer and what you say about it is the main course. What could be better than that.

Extremely short text is often referred to as "telegraph style," because this is how people wrote telegrams in the past to save money on the number of words. It basically means employing sentence fragments rather than full sentences, eliminating definite articles, using abbreviations, etc. Some speakers even delete much standard punctuation, notably periods, commas, and semicolons at the end of bullet points. Consider the following examples.

\section{Example Slide A. Conventional style of the text.}

The style of the text should be telegraphic (key words) in order to:

1. Minimize how much text the audience has to read on the screen

2. Refocus the audience's attention on the speaker so that he can elaborate on what they have read on the screen

\section{Example Slide B. Telegraphic style of text.}

Telegraphic (key words) to:

1. Minimize text the audience must read

2. Refocus audience attention on speaker for elaboration

Both of these examples give essentially the same information; however, they do not have the same impact. Example $A$ is heavy and tedious, and takes considerable time to read. Example $B$ is light and crispy, and takes only a moment to read. Over a series of 30 - 50 slides, which would you prefer?

Choosing the colors. Like every other aspect of a slide, its colors should aid understanding. Colors should not be chosen for their "esthetic value," because this often impedes understanding. Three of the most common mistakes are:

\section{Color combinations that damage readability.}

The classic example is white letters on a red background. The red tends to "swallow" the white, making the text difficult to read. Other typically poor combinations are white on blue, yellow on blue, blue on yellow, and red on black. 
Choose color combinations that reinforce readability.

\section{Too many colors.}

Many colors on the screen may be "attractive," but they are also confusing. In general, limit colors to three or four. Any more than this is almost certain to be detrimental.

\section{Color coding.}

Color coding is the practice of identifying related data on graphs and charts by assigning them the same color. This is a good idea in books, but not on slides.

First, it almost invariably requires more than four colors, often leading to poor combinations for readability (e.g. white on blue, red on black, etc.).

More importantly, it causes the eye to trace out the different color trails on the slide while the speaker is talking. This means the listeners will not really be listening to what you are saying because their attention will either be split or totally somewhere else.

Background. The terms "foreground" and "background" clearly indicate their purpose. The foreground contains materials put up front where they can be easily seen, because they are the stars of the slide.

The background is there to support the foreground, not to compete with it. In particular, the background should reinforce the text. Therefore keep the background simple. Avoid complex patterns and other "esthetic" artifices that:

1. Compete with the text for listener attention

2. Make the text difficult-and sometimes impossible-to read

Animation. Until fairly recently, slides were either $35 \mathrm{~mm}$ or overhead transparencies. By their very nature, they were fixed and couldn't move. With today's computer slide software, animation is not only possible, it is temptingly easy.

Don't be lured. Use animation to highlight key ideas, not to entertain.

If you are showing a flow chart, animation can emphasize the flow. If you are showing bullet points, animation can reinforce the importance of the general statement and then each piece of data supporting it.

Animation used for entertainment usually distracts from the idea or ideas the slide is supposed to be conveying. Flashing lights, spinning texts, cartoon characters moving in the background, and other "theatrical effects" may charm the eye, but they damage comprehension. 
Always remember slides are an integral part of the presentation, not an add-on. The principles and practices that underpin the oral component of the presentation are essentially the same as those that should underpin the visual component. Slides should never be designed to please the esthetic tastes of the presenter, but always in order to please the audience, i.e. enhance the communication. This is the only real reason for using slides in the first place.

In the next installment (CC15), we will extend the ideas presented in this essay. Specifically, we will discuss "How to Avoid Death by PowerPoint."

\section{HOMEWORK: Retrospective to Communication Corner No. 13}

\section{Exercise 1: Listen and Learn}

You were asked to closely listen to any speaker you admire (politician, business leader, celebrity, educator, friend, etc.) in an impromptu situation, and ask yourself why you admire him or her. I specified an impromptu situation (i.e. interview, news conference, company meeting, etc.) because this is where they really shine. They are required to speak largely off the cuff. They haven't spent hours of preparation as with a formal speech, yet sometimes it seems as if they have because there is hardly an um, ah, like, you know in earshot.

\section{Exercise 2: Try It Yourself}

You were asked to pay close attention to how you yourself speak in impromptu situations. You were asked to consciously try to avoid filler words (um, er, ah, you know, etc.), in part by divesting yourself of the false idea that they are somehow "natural." They aren't. Using filler words is a tic, a quirk, or a habit; what it is not is a force of nature.

I hope you did so, and were pleasantly surprised by the results.

Remember: A key to reducing and eliminating use of filler words is to recognize they are usually several ways of say the same thing, but there is seldom a "best way." So stop looking for it, just say what you have to say and move on. If something comes out of your mouth you think you could have said better, simply start your next sentence with "To be more precise...," and then say it better. This technique will not only keep your speech fluent, it will make you appear to be master of your subject rather than its apprentice. What could be better than that? 


\title{
CURRENT HOMEWORK
}

You have been given a number of criteria for designing effective slides.

1. Check any slides you may have produced in the past to see how closely they conform to these criteria. Be critical. The fact that you designed them, and may have expended considerable time and energy doing so, is irrelevant. If they don't work for the audience, they don't work. Whatever your good intentions, the time and energy you spent, while laudable, is simply beside the point.

2. Whenever you attend a presentation, which includes slides, check them to see how closely they conform to these criteria. Chances are you will find many of them do not. More importantly, you will probably find that this failure deeply damages the presentation. Fix this thought firmly in mind, and keep it uppermost in your thoughts whenever you prepare slides for you own presentations.

\begin{abstract}
About the Author
Philip Yaffe was born in Boston, Massachusetts, in 1942 and grew up in Los Angeles, where he graduated from the University of California with a degree in mathematics and physics. In his senior year, he was also editor-in-chief of the Daily Bruin, UCLA's daily student newspaper. He has more than 40 years of experience in journalism and international marketing communication. At various points in his career, he has been a teacher of journalism, a reporter/feature writer with The Wall Street Journal, an account executive with a major international press relations agency, European marketing communication director with two major international companies, and a founding partner of a specialized marketing communication agency in Brussels, Belgium, where he has lived since 1974. He is the author of more than 20 books, which can be found easily in Amazon Kindle.
\end{abstract}

DOI: $10.1145 / 3326538$ 